\title{
MET NP_000236.2:p.F1200I
}

National Cancer Institute

\section{Source}

National Cancer Institute. MET NP 000236.2:p.F12001. NCI Thesaurus. Code C162288.

A change in the amino acid residue at position 1200 in the hepatocyte growth factor receptor protein where phenylalanine has been replaced by isoleucine. 